\title{
Experimental and modeling study of kinetics for methane hydrate formation in a crude oil-in-water emulsion
}

\author{
Shranish Kar ${ }^{1} \cdot$ Himangshu Kakati $^{1} \cdot$ Ajay Mandal $^{1} \cdot$ Sukumar Laik $^{1}$
}

Received: 22 December 2015/Published online: 12 July 2016

(c) The Author(s) 2016. This article is published with open access at Springerlink.com

\begin{abstract}
A low-viscosity emulsion of crude oil in water can be believed to be the bulk of a flow regime in a pipeline. To differentiate which crude oil would and which would not counter the blockage of flow due to gas hydrate formation in flow channels, varying amount of crude oil in water emulsion without any other extraneous additives has undergone methane gas hydrate formation in an autoclave cell. Crude oil was able to thermodynamically inhibit the gas hydrate formation as observed from its hydrate stability zone. The normalized rate of hydrate formation in the emulsion has been calculated from an illustrative chemical affinity model, which showed a decrease in the methane consumption (decreased normalized rate constant) with an increase in the oil content in the emulsion. Fourier transform infrared spectroscopy (FTIR) of the emulsion and characteristic properties of the crude oil have been used to find the chemical component that could be pivotal in selfinhibitory characteristic of the crude oil collected from Ankleshwar, India, against a situation of clogged flow due to formation of gas hydrate and establish flow assurance.
\end{abstract}

Keywords Methane gas hydrates - Organic inhibitors · Chemical affinity model · Normalized rate constant . Asphaltenes

Ajay Mandal

mandal_ajay@hotmail.com

1 Department of Petroleum Engineering, Indian School of Mines, Dhanbad 826004, India

Edited by Yan-Hua Sun

\section{Introduction}

Way back in the 1930s, natural gas hydrates were discovered in gas transmission lines, frequently at temperatures above the ice point. Many chloride salts, methanol, and monoethylene glycol are considered for hydrate inhibition in pipelines, but the hydrate problem in pipelines is still growing with the deep offshore production, increase in water cuts, and existence of multicomponent flow. Uneconomic thermodynamic inhibitors have been replaced by low dosage hydrate inhibitors (LDHI). In the hydrocarbon industry, emulsions can be encountered in almost all phases of oil and gas production, inside the reservoirs, well bores, and well heads and in transportation through pipelines. Irrespective of the amount of water in the emulsified system, hydrates could form in the emulsion at particular pressure and temperature conditions, which consequently leads to plugging of pipelines due to agglomeration of the hydrate particles into a large mass (Greaves et al. 2008; Mu et al. 2014). In more stable emulsions, there is a higher rate of hydrate formation as small droplets increase the surface area of contact between gas and water. In the oil-in-water $(\mathrm{O} / \mathrm{W})$ emulsion, the large surface contact between water and gas allows maximum mass transfer which increases the gas consumption rate (Douglas et al. 2009; Xiang et al. 2013). Talatori and Barth (2011) found that the nucleation time for methane gas hydrate formation depended inversely on the driving force, i.e., subcooling at a constant water cut and expectedly, the nucleation time decreased when the water cut increased at a constant temperature

From the solubility aspect, Xiang et al. (2013) suggested that the solubility of gas in emulsions decreased with an increase in the water cut at a given pressure. Beyond these physical parameters, Mohammadi et al. (2006) indicated that inherent natural components in crude oil resisted 
agglomeration and inhibited the hydrate growth by coating them during hydrate formation in the water-in-oil (W/O) emulsions.

Crude oil as a whole is composed of saturates, aromatics, resins, and asphaltenes. Sinquin et al. (2001) founded that asphaltenes and organic acids have played a major role in the emulsion stability and, as a consequence, in hydrate agglomeration and plugging. They observed delayed formation and smooth crystallization of hydrates in crude oil of higher asphaltene content and rapid crystallization of methane hydrates in crude oil of lower asphaltene content. Davies et al. (2010) reported the mass transfer rates across methane hydrate films grown at hydrocarbon-water interfaces in a quiescent system, as a function of subcooling and the age of the film. Hossein et al. (2011) showed the electrical repulsive force in an $\mathrm{O} / \mathrm{W}$ emulsion and the steric effect in a W/O emulsion to be the mechanism behind emulsion stabilization by asphaltenes. In the case of gas hydrates, the wax would reduce the subcooling by acting as nucleation sites and the crude oil of increased lighter fractions would increase the dissociation temperature of gas hydrates. Mu et al. (2014) studied the inversion of an emulsion with a particle analyzer and a conductivity meter during dissociation of methane hydrates.

An O/W emulsion was used in this study to investigate the effect of crude oil on thermodynamics and kinetics of methane hydrate formation. The equilibrium pressure and temperature of hydrate formation in the emulsion were measured and compared with respect to pure water system. The rate of hydrate formation has been studied by a chemical affinity model (Roosta et al. 2013).

\section{Experimental}

\subsection{Material}

All the experiments were performed with $99.99 \%$ pure methane gas (collected from the Chemtron Science Laboratory, Navi Mumbai, India) and double-distilled water with a dynamic viscosity of $1.002 \mathrm{cP}$ and specific conductance $(\kappa)$ of $2 \mu \mathrm{S} / \mathrm{cm}$ (approximately) at $25^{\circ} \mathrm{C}$. Crude oil was collected from the Ankleshwar field, India. All materials were used with no further purification or modification of their properties. The physicochemical characteristics of crude oil are given in Table 1.

\subsection{Apparatus}

The details of apparatus used in this study were mentioned in our previous work (Kakati et al. 2014). Briefly, the high pressure autoclave consisted of a constant volume hydrate cell with a pressure rating up to $20.68 \mathrm{MPa}$. A stethoscope camera, thermocouples, and a digital pressure gauge were incorporated into the cell. The cell was equipped with a PT100 probe to measure the temperature inside the cell, and the uncertainty of the measurement was $\pm 0.05{ }^{\circ} \mathrm{C}$. A magnetic stirrer with adjustable rotation speed (up to $1000 \mathrm{rpm}$ ) was used to agitate the test fluid in the cell. The cell was dipped in a thermostatic bath filled with a thermostatic fluid (a mixture of $85 \%$ water and $15 \%$ glycol) to control its temperature within the range of -10 to $60{ }^{\circ} \mathrm{C}$. Every experiment was repeated three times to check the reproducibility. It has been found that pressure variation was within $\pm 0.1 \mathrm{MPa}$.

\subsection{Methods}

\subsubsection{Preparation of emulsion}

An emulsion was prepared by stirring, not just to mix the liquids but to disperse one of them in the other. A 4-blade impeller stirrer, (REMI RQ 20 PLUS), was used to prepare the emulsion at 2000-2500 rpm so that the oil was properly dispersed in the water for various water cuts. After mixing for $5 \mathrm{~h}$, the mixture was allowed to settle in a separating funnel to separate the emulsion for study from the heavier or waxy components which did not disperse in the continuous phase, i.e., water. After separating the emulsion from the separating funnel its hydrocarbon content was measured in parts per million (ppm) using an Infracal TOG/TPH analyzer (Wilks) to detail the actual oil content in the emulsion. Three $\mathrm{O} / \mathrm{W}$ emulsion samples with the oil content of $870,1880,3560 \mathrm{ppm}$ were prepared for the hydrate study.

\subsubsection{Procedure}

Our previous work described the experimental procedure in detail (Kakati et al. 2014). The cell was filled with $120 \mathrm{~mL}$ of the prepared emulsion and methane gas was charged up to $11 \mathrm{MPa}$ at $20^{\circ} \mathrm{C}$. The cell was then cooled in steps of $2{ }^{\circ} \mathrm{C}$ per hour in the programmable bath and allowed to

Table 1 Physicochemical characteristics of crude oil

\begin{tabular}{llllll}
\hline $\begin{array}{l}\text { Density at } 15.5{ }^{\circ} \mathrm{C}, \\
\mathrm{kg} / \mathrm{m}^{3}\end{array}$ & $\begin{array}{l}\text { Specific gravity } \\
\text { at } 15.5{ }^{\circ} \mathrm{C}\end{array}$ & $\begin{array}{l}\text { API gravity at } \\
15.5{ }^{\circ} \mathrm{C},{ }^{\circ} \mathrm{API}\end{array}$ & $\begin{array}{l}\text { Viscosity at } \\
30{ }^{\circ} \mathrm{C}, \mathrm{cP}\end{array}$ & $\begin{array}{l}\text { Acid number, } \\
\mathrm{mg} \mathrm{KOH} / \mathrm{g}\end{array}$ \\
\hline 855.60 & 856.10 & 35.77 & 525 & $\begin{array}{l}\text { Pour point, } \\
{ }^{\circ} \mathrm{C}\end{array}$ \\
\hline
\end{tabular}


dwell for $1 \mathrm{~h}$ at each step to equilibrate. To observe the dissociation of methane hydrates, the entire cell was heated slowly at $1{ }^{\circ} \mathrm{C} / \mathrm{h}$ step wise so that the equilibrium of the system was not disturbed.

To measure the inhibition time or induction time of hydrate formation, the cell was cooled from a pressure and temperature condition (determined by the hydrate stability zone (HSZ) experiment) where hydrate does not exist, to that temperature (hydrate formation temperature) where hydrate forms. The time taken between start of experiment $\left(t_{\mathrm{s}}\right)$ and hydrate onset time $\left(t_{\mathrm{o}}\right)$ is the induction time of hydrate formation.

\subsubsection{Fourier transform infrared spectroscopy (FTIR)}

A Perkin-Elmer Spectrum Two, FT-IR instrument (USA) was used to obtain the spectra of the $\mathrm{O} / \mathrm{W}$ emulsions between 400 and $4000 \mathrm{~cm}^{-1}$ wavelength. The IR spectrum of the pellet was recorded and 100 scans were collected. The transmittance versus wavenumber plot for the $\mathrm{O} / \mathrm{W}$ emulsions with the oil content of 1880 and $3560 \mathrm{ppm}$, respectively, are shown in Fig. 1. The FTIR spectroscopy of the crude oil has been described in our previous work by Mandal et al. (2015).

On investigating the FTIR spectroscopic plot from wavenumber of 4000 to $500 \mathrm{~cm}^{-1}$, the alkyl group was observed to be present from -C-H stretching bands in 2862 and $2931 \mathrm{~cm}^{-1}$. This band is relevant in most organic molecules. The presence of $-\mathrm{O}-\mathrm{H}$ can be anticipated from a broad strong band at $3430 \mathrm{~cm}^{-1}$. $-\mathrm{O}-\mathrm{H}$ and $-\mathrm{C}-\mathrm{O}$ stretch around $1369 \mathrm{~cm}^{-1}$ indicates the presence of the carbonyl group which might be due to the carboxylic acid present in the crude oil. On the other hand, this could be indicating an

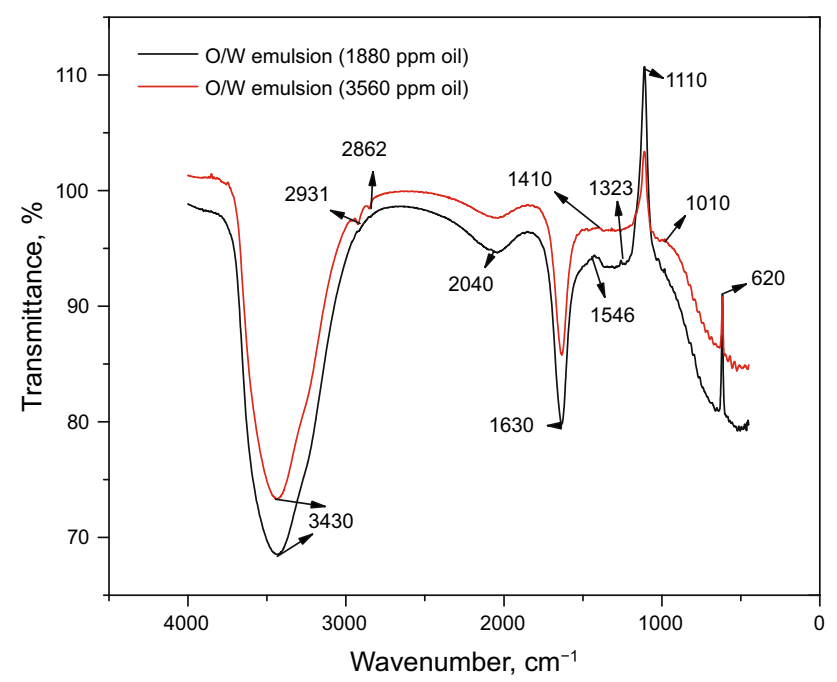

Fig. 1 FTIR plot of transmittance versus wavelength for the O/W emulsions of oil content of 1880 and $3560 \mathrm{ppm}$ ester functional group present instead of carboxylic acid to justify the low acid number per gram of $\mathrm{KOH}$ for crude oil observed by Kakati et al. (2014). A weak band known as overtones showing at around $2040 \mathrm{~cm}^{-1}$ and out of plane-_"oop" bands from $900-675 \mathrm{~cm}^{-1}$ suggest aromatic groups. In addition to that, carbon double bonding is confirmed from a sharp peak at $1638 \mathrm{~cm}^{-1}$ due to $-\mathrm{C}=\mathrm{C}$ stretch. Furthermore, FTIR of crude oil (Mandal et al. 2015) and Fig. 1 show a peak at $1410 \mathrm{~cm}^{-1}$ which is the effect of $-\mathrm{C}-\mathrm{C}$ stretching in rings of aromatic components. SARA analysis of the crude oil had shown an appreciable weight percent of aromatics and asphaltenes (Kakati et al. 2014) which augments the FTIR interpretation done here. A sharp peak at $1110-1000 \mathrm{~cm}^{-1}$ represents $-\mathrm{C}-\mathrm{N}$ stretch in aliphatic amines to supplement the band for $\mathrm{N}-\mathrm{H}$ at $3400-3250 \mathrm{~cm}^{-1}$.

Out of a wide range of highly complex chemical compounds, such as alkanes, aromatics, cycloalkanes, resins, and asphaltenes present in the crude oil, asphaltenes, waxes, and resins are believed to stabilize the $\mathrm{O} / \mathrm{W}$ emulsion (Greaves et al. 2008). These act as extraneous materials in the interfacial film of oil and water to suppress the mechanism for emulsion break down and to stabilize the interface (Mandal et al. 2010).

\section{Results and discussion}

Crude oil thermodynamically inhibits the formation of methane gas hydrate as observed in our previous work by Kakati et al. (2014).

\subsection{Comparison of hydrate formation curve}

The curves of methane gas hydrate formation in $\mathrm{O} / \mathrm{W}$ emulsions of different oil contents are shown with pure water in Fig. 2 and the corresponding temperature and pressure drops are listed in Table 2.

Table 2 shows that the formation temperature shifts to lower values in the $\mathrm{O} / \mathrm{W}$ emulsion with respect to pure water. The pressure drop during hydrate formation in pure water is more than the corresponding pressure drop during hydrate formation in the $\mathrm{O} / \mathrm{W}$ emulsion.

\subsection{Comparison of hydrate dissociation curve}

The dissociation curves of gas hydrate in $\mathrm{O} / \mathrm{W}$ emulsions of different oil contents are shown along with pure water in Fig. 3. In the $\mathrm{O} / \mathrm{W}$ emulsion, the hydrate dissociation curve moves to higher pressure for a given temperature as seen in Fig. 3.

It is important to observe here that the $\mathrm{O} / \mathrm{W}$ emulsion has shifted the equilibrium temperature substantially in the 


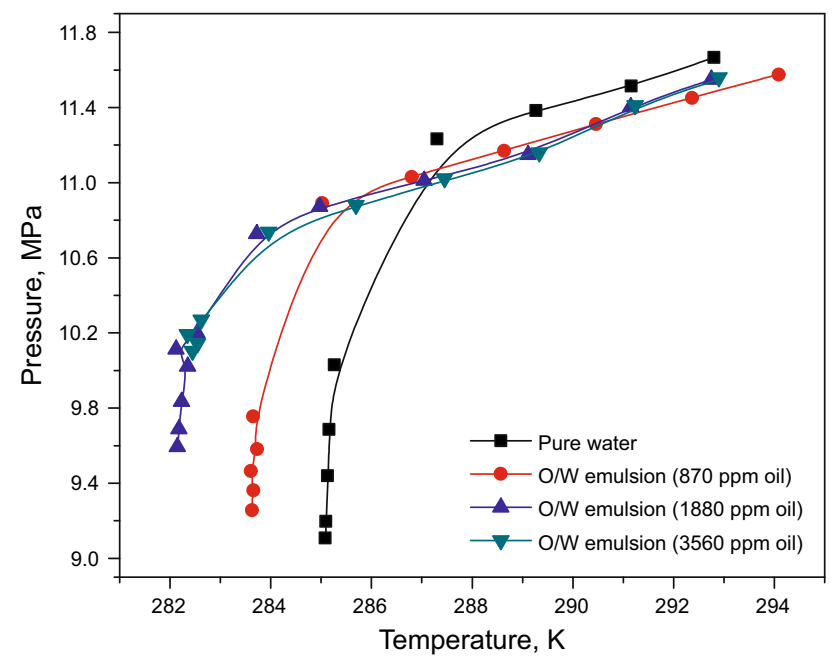

Fig. 2 Temperature versus pressure profiles of methane hydrate formation in pure water and $\mathrm{O} / \mathrm{W}$ emulsions

higher pressure region or has shifted the equilibrium pressure to a higher region thus indicating a similar action which can be due to their larger molecular structures. The inhibition power of these samples is due to the affinity of the oxygen atoms of the $-\mathrm{O}-\mathrm{H}$ group for neighboring water molecules. Thus, water molecules are prevented from forming hydrogen-bonded cages to capture gaseous guest molecules. It may be speculated that the extent to form hydrogen bonds with water molecules depend on the size of these chemicals. The hydrogen bonding of inhibitor with water may be hindered with an increase in the inhibitor size. Therefore, water molecules may not be substantially restricted by the inhibitor of larger sizes to form hydrate cages.

\subsection{Chemical affinity modeling for kinetics of hydrate formation}

The chemical affinity model (Roosta et al. 2013) is one of the thermodynamic-based approaches that can be applied for hydrate formation kinetics. This model is independent of the parameters such as heat and mass transfer coefficients which are difficult to determine and only macroscopic properties such as pressure and temperature are needed for this model. When bulk techniques such as gas uptake measurements in closed isothermal systems are used for determining the kinetics of hydrate formation, a gradual conversion of gas to hydrate is normally observed, suggesting a relatively homogeneous process that could be modeled using a kinetics parameter. The chemical affinity approach has been used for description of chemical reactions in isothermal-isochoric systems. So, it is applicable for systems with complex additives like crude oil.

For a chemical reaction, the chemical affinity $\left(A_{i}\right)$ is a generalized driving force which is given by the following expression suggested by Roosta et al. (2013):
Table 2 Hydrate formation parameters for the $\mathrm{O} / \mathrm{W}$ emulsion (3560 ppm oil) and pure water

\begin{tabular}{llll}
\hline Test sample & Formation pressure, MPa & Formation temperature, K & Pressure drop, MPa \\
\hline Pure water & 10.03 & 285.27 & 0.93 \\
O/W emulsion & 10.72 & 283.96 & 0.63 \\
\hline
\end{tabular}

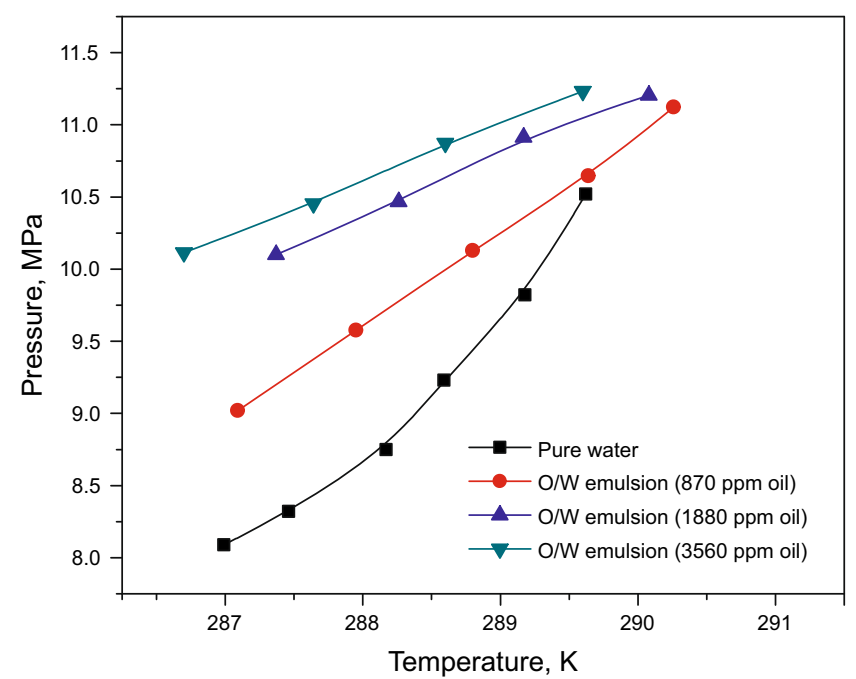

Fig. 3 Temperature versus pressure profiles of methane hydrate dissociation in the O/W emulsions and pure water 
$A_{i}=A_{i}^{\mathrm{o}}-R T \ln \left(Q_{i}\right)$,

where $A_{i}^{\mathrm{o}}$ is the affinity of the components at their standard states, $\mathrm{J} \mathrm{mol}{ }^{-1}$, and $A$ is only a function of temperature; $Q_{i}$ is the activity ratio for the $i$ th component. At the equilibrium condition $A_{i}=0$ so $A_{i}^{\mathrm{o}}=R T \ln (K)$ in which $K$ denotes the thermodynamic equilibrium constant. Substituting $A_{i}^{\text {o }}$ into Eq. (1), $A_{i}$ can be written as,

$A_{i}=-R T \ln \left(\beta_{Q_{i}}\right)$ where, $\beta_{Q_{i}}=\frac{Q_{i}}{K}$.

Experimentally, it has been established that, the affinity decay rate $\AA_{T, V}$ is inversely proportional to time (Garfinkle 2000) which can be expressed as

$\AA_{T, V}=A_{\mathrm{r}}\left(\frac{1}{t}\right)+C_{1}$,

where $A_{\mathrm{r}}$ is the proportionality constant and denotes the affinity rate constant; and $C_{1}$ is any arbitrary constant. Further for a closed, fixed volume, and constant temperature system, the affinity decay rate can be expressed as follows:

$\stackrel{\AA}{A}_{T, V}=\left(\frac{\partial A_{i}}{\partial t}\right)_{T, V}$.

Again at the equilibrium condition, the affinity decay rate is zero. Thus, considering the time needed for the system to reach the equilibrium to be $t_{K}$, Eq. (3) can be expressed as

$\stackrel{\AA}{A, V}_{T}=A_{\mathrm{r}}\left(\frac{1}{t}-\frac{1}{t_{K}}\right)$.

From Eqs. (4) and (5), one obtains the following equation:

$\left(\frac{\partial A_{i}}{\partial t}\right)_{T, V}=A_{\mathrm{r}}\left(\frac{1}{t}-\frac{1}{t_{K}}\right)$.

Upon integrating Eq. (6) from the initial time $t_{i}$ to the time required reaching the equilibrium $t_{K}$

$\frac{A_{i}}{R T}=-\frac{A_{\mathrm{r}}}{R T}\left[-\ln \left(\frac{t_{i}}{t_{K}} \exp \left(1-\frac{t_{i}}{t_{K}}\right)\right)\right]$.

Equation (7) can be used to correlate the parameters of the chemical affinity model with experimental values versus time. Even though the hydrate formation process is not a chemical reaction, $A_{i}$ at different conditions can be measured, by considering the extent of the hydrate formation process with time in terms of pressure of gas in each elapsed time. Instead of activity, the amount of gas consumed $n_{\mathrm{c}}$ during hydrate formation is used to show the extent of hydrate formation. Hence, Eq. (2) is expressed in the ratio,
$\beta_{Q_{i}}=\frac{n_{\mathrm{c} i}}{n_{\mathrm{cf}}}=\frac{n_{\mathrm{o}}-n_{i}}{n_{\mathrm{o}}-n_{\mathrm{f}}}$,

where subscript o stands for the initial condition and subscript $\mathrm{f}$ for the equilibrium condition.

$n_{\mathrm{o}}=\frac{P_{\mathrm{o}} V}{Z_{\mathrm{o}} R T} \& n_{\mathrm{f}}=\frac{P_{\mathrm{f}} V}{Z_{\mathrm{f}} R T}$,

where $P_{\mathrm{o}}$ and $P_{\mathrm{f}}$ are the initial and equilibrium pressures, respectively. Substituting $n_{\mathrm{o}}$ and $n_{\mathrm{f}}$ into Eq. (8) and the expression for $\beta_{Q_{i}}$ in Eq. (2), $A_{i}$ can be calculated from

$\frac{A_{i}}{R T}=-\ln \left(\frac{n_{\mathrm{c} i}}{n_{\mathrm{cf}}}\right)=-\ln \left(\frac{\frac{P_{\mathrm{o}}}{Z_{\mathrm{o}}}-\frac{P_{i}}{Z_{i}}}{\frac{P_{\mathrm{o}}}{Z_{\mathrm{o}}}-\frac{P_{\mathrm{f}}}{Z_{\mathrm{f}}}}\right)$.

Further substituting Eq. (10) into Eq. (8) the following equation can be obtained:

$\frac{n_{\mathrm{c} i}}{n_{\mathrm{cf}}}=\frac{\frac{P_{\mathrm{o}}}{Z_{\mathrm{o}}}-\frac{P_{i}}{Z_{i}}}{\frac{P_{\mathrm{o}}}{Z_{\mathrm{o}}}-\frac{P_{\mathrm{f}}}{Z_{\mathrm{f}}}}=\left[\ln \left(\frac{t_{i}}{t_{K}} \exp \left(1-\frac{t_{i}}{t_{K}}\right)\right)\right]^{-\frac{A_{\mathrm{r}}}{R T}}$,

where $-\frac{A_{\mathrm{r}}}{R T}$ is the kinetic parameter of this model. The absolute value of slope $\left(\left|\frac{A_{\mathrm{r}}}{R T}\right|\right)$ can be a normalized rate constant. So, the value of this slope can be employed for investigating the effects of additives in the system on hydrate formation kinetics. Plotting $\ln \left(\frac{n_{\mathrm{ci}}}{n_{\mathrm{cc}}}\right)$ versus $\ln \left(\frac{t_{i}}{t_{K}} \exp \left(1-\frac{t_{i}}{t_{K}}\right)\right)$ a straight line through origin with a slope of $-\frac{A_{\mathrm{r}}}{R T}$ is obtained. Figure 4 shows the plot for all the three concentrations of emulsions and the linear trend line gives the slope for each of them at various stages.

In Fig. 4, it is observed that the slope of curves changes with a change in oil concentration in the $\mathrm{O} / \mathrm{W}$ emulsion.

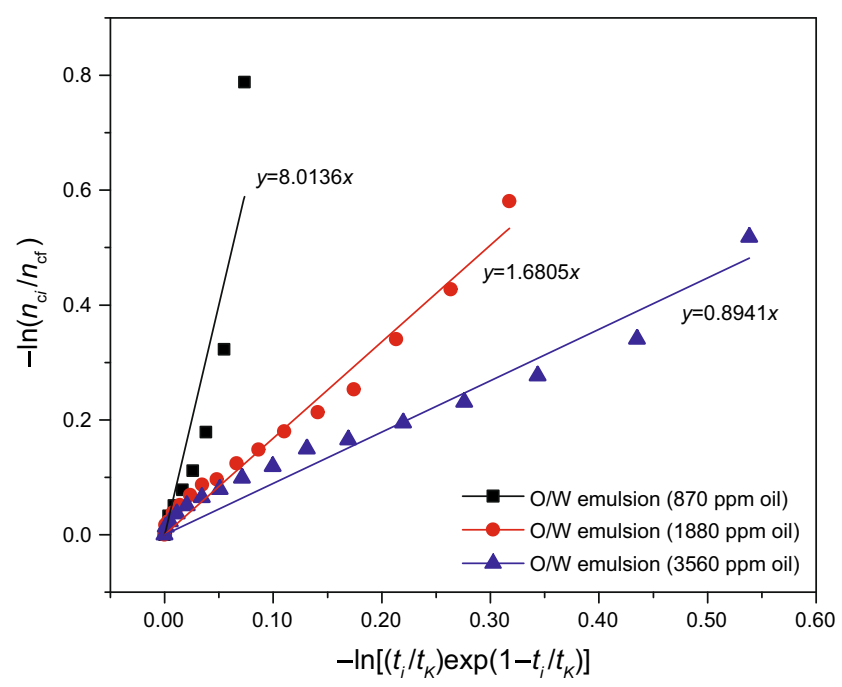

Fig. $4-\ln \left(\frac{n_{\mathrm{ci}}}{n_{\mathrm{cf}}}\right)$ versus $-\ln \left(\frac{t_{i}}{t_{K}} \exp \left(1-\frac{t_{i}}{t_{K}}\right)\right)$ dimensionless plot for finding the rate constant $\left(\left|\frac{A_{\mathrm{r}}}{R T}\right|\right)$ 
Thus, from the basic rate equation (Sloan and Koh 2007), the rate of consumption of gas can be written as

Rate of consumption $=$ rate constant $\times$ driving force .

Keeping the driving force constant, the rate of consumption decreases as the rate constant decreases. Thus, from the normalized rate constant listed in Table 3, we see that there must be a decrease in gas consumption which was experimentally seen in our previous work by Kakati et al. (2014).

In Fig. 5, a change in the slope of the curve is observed with respect to time for a sample. This is due to different rates of hydrate formation which gives different reaction rates and hence different rate constants. Table 3 shows the methane hydrate formation rates in $\mathrm{O} / \mathrm{W}$ emulsions. Initially the formation rate of hydrate is high, and then it decreases with time.

Table 3 Rate constant of the formation of methane hydrates in $\mathrm{O} / \mathrm{W}$ emulsions

\begin{tabular}{lll}
\hline $\begin{array}{l}\text { Oil content in the } \\
\text { O/W emulsion, ppm }\end{array}$ & Rate constant & $\begin{array}{l}\text { Normalized rate } \\
\text { constant }\end{array}$ \\
\hline 870 & $K_{11} 10.53950$ & 8.0136 \\
& $K_{12} 3.533986$ & \\
& $K_{13} 8.474374$ & \\
& $K_{21} 2.644888$ & 1.6805 \\
1881 & $K_{22} 1.220637$ & \\
& $K_{23} 2.241379$ & \\
3560 & $K_{31} 2.242573$ & 0.8941 \\
& $K_{32} 0.676824$ & \\
& $K_{33} 2.242573$ & \\
\hline
\end{tabular}

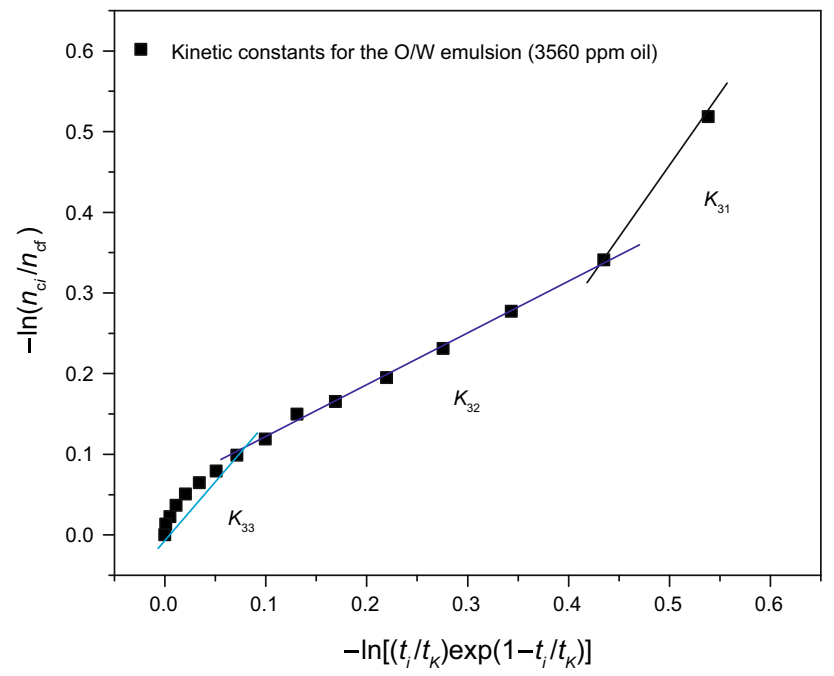

Fig. $5-\ln \left(\frac{n_{\mathrm{ci}}}{n_{\mathrm{cf}}}\right)$ versus $-\ln \left(\frac{t_{i}}{t_{K}} \exp \left(1-\frac{t_{i}}{t_{K}}\right)\right)$ dimensionless plot for finding the rate constant $\left(\left|\frac{A_{\mathrm{r}}}{R T}\right|\right)$ in case of the $\mathrm{O} / \mathrm{W}$ emulsion (3560 ppm oil)

\section{Conclusion}

From the formation and dissociation of methane hydrates in the $\mathrm{O} / \mathrm{W}$ emulsion, a thermodynamic inhibition was observed by crude oil due to a reduction of the chemical potential of water. The equilibrium $P-T$ curve shifted toward a higher pressure and lower temperature zone when the concentration of oil in the emulsion increased. It was inferred from the FTIR that there was less chance of the presence of carboxylic acid groups (or if present not in a detectable amount). This was also suggested from the low acid number of crude oil. The functional groups present were observed from the FTIR which showed $-\mathrm{OH}$, aromatic, and amide groups. From this and satisfactory stability of the $\mathrm{O} / \mathrm{W}$ emulsion, a consensus was that the surface active asphaltenes might be responsible for such organic inhibition. As a very small lag time was observed during the kinetics study, the emulsion was inferred not to be a kinetic inhibitor. The chemical affinity model showed a decrease in the normalized rate constant for gas consumption as the percentage of oil increased.

Acknowledgments We gratefully acknowledge the financial assistance provided by University Grants Commission, New Delhi, India, under Special Assistance Program (SAP) to the Department of Petroleum Engineering, Indian School of Mines, Dhanbad, India.

Open Access This article is distributed under the terms of the Creative Commons Attribution 4.0 International License (http://crea tivecommons.org/licenses/by/4.0/), which permits unrestricted use, distribution, and reproduction in any medium, provided you give appropriate credit to the original author(s) and the source, provide a link to the Creative Commons license, and indicate if changes were made.

\section{References}

Davies SR, Lachance JW, Sloan ED, Koh CA. High-pressure differential scanning calorimetry measurements of the mass transfer resistance across a methane hydrate film as a function of time and subcooling. Ind Eng Chem Res. 2010;49(23):12319-26. doi:10.1021/ie1017173.

Douglas T, Miller KT, Sloan ED. Methane hydrate formation and an inward growing shell model in water-in-oil dispersions. Chem Eng Sci. 2009;64(18):3996-4004. doi:10.1016/j.ces.2009.05. 051 .

Garfinkle M. The thermodynamic natural path in chemical reaction kinetics. Discret Dyn Nat Soc. 2000;4(2):145-64. doi:10.1155/ S1026022600000145.

Greaves D, Boxall J, Mulligan J, Sloan ED, Koh CA. Hydrate formation from high water content-crude oil emulsions. Chem Eng Sci. 2008;63(18):4570-9. doi:10.1016/j.ces.2008.06.025.

Hossein M, Chapoy A, Tohidi B. Phase inversion in water-oil emulsions with and without gas hydrates. Energy Fuel. 2011;25(12):5736-45. doi:10.1021/ef201374v.

Kakati H, Kar S, Mandal A, Laik S. Methane hydrate formation and dissociation in oil-in-water emulsion. Energy Fuel. 2014;28(7):4440-6. doi:10.1021/ef500681z. 
Mandal A, Kar S, Kumar S. Synergistic effect of mixed surfactant (Tween 80 and SDBS) on wettability alteration of oil wet quartz surface. J Dispers Sci Technol. 2015. doi:10.1080/01932691. 2015.1089780.

Mandal A, Samanta A, Bera A, Ojha K. Characterization of oil-water emulsion and its use in enhanced oil recovery. Ind Eng Chem Res. 2010;49:12756-61. doi:10.1021/ie101589x.

Mohammadi AH, Ji H, Burgass R W, Ali AB, Tohidi B. Gas hydrates in oil systems. In: SPE Europec/EAGE annual conference and exhibition, 12-15 June, Vienna, Austria; 2006. doi:10.2118/ 99437-MS.

Mu L, Li S, Ma QL, Zhang K, Sun CY, Chen GJ, Liu B, Yang LY. Experimental and modeling investigation of kinetics of methane gas hydrate formation in water-in-oil emulsion. Fluid Phase Equilib. 2014;362:28-34. doi:10.1016/j.fluid.2013.08.028.

Roosta H, Khosharay S, Varaminian F. Experimental study of methane hydrate formation kinetics with or without additives and modeling based on chemical affinity. Energy Convers Manag. 2013;76:499-505. doi:10.1016/j.enconman.2013.05.024. Sinquin A, Bredzinsky X, Beunat V. Kinetic of hydrates formation: influence of crude oils. In: SPE annual technical conference and exhibition, 30 September-3 October, New Orleans, Louisiana, 2001. doi:10.2118/71543-MS.

Sloan ED, Koh CA. Clathrate hydrates of natural gases. 3rd ed. Boca Raton: CRC Press; 2007.

Talatori S, Barth T. Rate of hydrate formation in crude oil/gas/water emulsions with different water cuts. J Pet Sci Eng. 2011;80(1):32-40. doi:10.1016/j.petrol.2011.10.010.

Xiang CS, Peng BZ, Liu H, Sun CY, Chen GJ, Sun BJ. Hydrate formation/dissociation in (natural gas + water + diesel oil) emulsion systems. Energies. 2013;6(2):1009-22. doi:10.3390/ en6021009. 